\title{
CITACIÓN Y REFERENCIACIÓN EN EL ÁMBITO DE LA FILOSOFÍA: PERSONALIZACIÓN DE ESTILOS INTERNACIONALES MEDIANTE GESTORES BIBLIOGRÁFICOS
}

\author{
QUOTATION AND REFERENCING IN \\ THE PHILOSOPHICAL SPHERE: THE \\ PERSONALIZATION OF INTERNATIONAL STYLES \\ USING REFERENCE MANAGEMENT SOFTWARE
}

\author{
Gemma MuÑOZ-Alonso* \\ Universidad Complutense de Madrid
}

RESUMEN: La transmisión del mensaje filosófico necesita concretarse en una serie de rasgos formales, rasgos que van desde una correcta citación y referenciación de los argumentos presentados, hasta una pulcra y rigurosa presentación ortotipográfica de las referencias bibliográficas empleadas. La tarea puede acometerse manualmente, lo cual supone un trabajo lento y complicado, o bien utilizar algunos de los gestores bibliográficos disponibles en la actualidad, como ProCite, RefWorks, EndNote o Zotero. Este artículo trata, en once epígrafes, de ofrecer la posibilidad de personalizar la citación y referenciación respetando la normativa internacional y adaptándola a la ortotipografía española. En una palabra, orientar al filósofo, al estudiante, al docente, en la tarea de abordar un trabajo académico con garantías de éxito.

Palabras clave: Aparato crítico. Citación de fuentes. Referenciación de materiales especiales. Trabajo académico. Gestores Bibliográficos. EndNote. Sistema Harvard. Referencias Bibliográficas.

Авstract: The transmission of the philosophical message needs to be made concrete in a series of formal features, features that range from a correct quotation and referencing of the arguments presented, to a neat and rigorous orthotypographic presentation of bibliographic references. The task can be done manually, a slow and

\footnotetext{
* E-mail de la autora: gemma@ucm.es
} 
complicated process, or using Reference Management Software, such as ProCite, RefWorks, EndNote or Zotero. This article intends, in eleven parts, to offer the possibility to personalize the method of citation and referencing following international norms and adapting them to Spanish orthotypograhy. In short, to help the philosopher, the student, the teacher, in the task of creating an academic paper with guaranteed success.

KeYwords: Critical background. Source quotation. Material reference. Academic paper. Harvard System. Bibliographical refrences. Reference Management Software. EndNote.

\section{Introducción}

Escribir sobre citación y referenciación en al año 2012 puede carecer de interés, pero no en el campo concreto de la filosofía. Es cierto que en otros campos, como biomedicina, física, y un largo etcétera, citar o referenciar fuentes de información en un trabajo académico o en un artículo de investigación, no supone, en principio, una tarea engorrosa ni compleja. La presencia de los gestores bibliográficos es, en determinados campos, imprescindible. Con la ayuda de estos productos, de ProCite a Zotero, se pueden incorporar hasta 100.000 referencias en las bibliografías o bibliotecas creadas por el investigador. La citación, en el entramado textual, tampoco presenta dificultades, salvo cuando existe demasiada información y puede dificultar la lectura y la comprensión. En el campo de la filosofía la situación es distinta, por varias razones.

Primero, en filosofía existe cierta tendencia a la escrupulosidad académica, lo cual supone citar las fuentes primarias utilizadas conforme a ediciones canónicas o avaladas científicamente, conservando una notación específica, mencionando el traductor o la edición correspondiente. Esta circunstancia afecta principalmente a los flósofos clásicos, entendiendo con ello aquellos autores como Platón, Santo Tomás, Descartes, Kant, Hegel, Schopenhauer o Heidegger, entre otros muchos, desde la Antigüedad hasta, cabría decir, el siglo XX. La citación o referenciación con algunos estilos, como el sistema Harvard, no se adapta, como detallaremos más adelante, con facilidad en la documentación de fuentes primarias.

Segundo, en cuanto a fuentes de información secundarias, la prestación que ofrecen los gestores es, sin ninguna duda, crucial. El filósofo utiliza una gran cantidad de documentación a lo largo de su trayectoria académica e investiga- 
dora, recursos de todo tipo en diferentes soportes: monografías impresas o libros electrónicos sobre o de diferentes filósofos, artículos sobre diversas temáticas (en soporte papel o electrónico), documentos en pdf, textos en CD-ROM, páginas web de filosofía o en torno a la filosofía, elementos multimedia que recogen diferentes documentos (entrevistas, conferencias, eventos filosóficos), o películas sobre filosofía o cercanas a la filosofía.

Esta proliferación de información y cambios en cuanto al soporte y tipos de recursos ha creado la necesidad de alguna forma de normalización para dotar a la citación y referenciación bibliográfica de cierta uniformidad y coherencia, independientemente del tipo de soporte, si bien los recursos electrónicos experimentan, como detallaremos en este artículo, una citación y referenciación peculiar, donde se atiende a la fecha de consulta y al tipo de soporte, además de referenciar la localización del recurso en cuestión.

A decir verdad, tanto organismos como la ISO, como las universidades de Harvard, Oxford, Chicago, o instituciones como la Modern Language Association (MLA), o la American Pshychological Association (APA) han propuesto desde hace bastantes años y adaptándose a los nuevos recursos, normas específicas. En España también contamos con propuestas de gran calidad; los estudios de Assumpció Estivill y Cristóbal Urbano (Universidad de Barcelona), Bonifacio Martín Galán y Eva Méndez (Universidad Carlos III), o María Jesús Lamarca Lapuente (Universidad Complutense de Madrid), son ejemplos de ello. Asimismo, Bibliotecas de diferentes universidades, de Alberta o Laval (ambas en Canadá), de Alcalá de Henares, de La Laguna, de La Rioja, de la UNED, o de la Universidad de Sevilla, entre otras muchas, ofrecen, en línea, normativa internacional sobre la temática. ${ }^{1}$

Pues bien, en este artículo vamos a tratar aspectos muy importantes para llevar a cabo un trabajo académico con garantías de éxito. Nos vamos a ocupar de las citas que solemos poner en el entramado textual de nuestro trabajo, de cómo debemos destacarlas, de cómo podemos decir al lector que hemos omitido una parte del texto original, o de cómo podemos tocar el texto sin alterarlo. Asimismo, vamos a referirnos al Sistema MLA y a la implementación del Sistema Harvard en el ámbito de la filosofía. En un quinto epígrafe hablaremos de las notas, porque aunque pueden ser lo mismo citas y notas, también pueden comportarse de forma independiente; en este contexto mencionaremos los

\footnotetext{
1 infra Bibliografía.
} 
distintos tipos de notas que podrían conformar el denominado aparato crítico, muy ponderado por profesores y por la comunidad científica en general. Las remisiones serán también objeto de nuestro estudio, ya que podemos indicar al lector que se vaya fuera del trabajo, y coteje o compare la información que ofrecemos, o bien que vaya a alguna parte del trabajo, donde tratamos con más amplitud la temática. Pues bien, indicaremos cuáles son los signos que precisamos utilizar para esas indicaciones. El sexto bloque temático aborda las Referencias bibliográficas que es necesario registrar en el trabajo, ya que un trabajo académico no es un ensayo, una novela, sino que es una construcción cimentada en una serie de fuentes. Saber recoger bien esas fuentes es crucial, porque de no hacerlo se pierden en el océano de la mala información; se convierten en ruido informativo. También nos referiremos a la buena presentación de una Bibliografía y de unas Referencias bibliográficas, y a la alfabetización de las fuentes en función de su origen. El séptimo epígrafe lo dedicaremos a la presentación de las Referencias bibliográficas en el Sistema Harvard. El octavo apartado trata de la referenciación de materiales especiales. A continuación abordaremos un tema de gran actualidad, y es el uso por parte del investigador de los gestores bibliográficos, los cuales suponen una ayuda imprescindible a la hora de recopilar material, de citar documentos en el trabajo académico o bien compartir bibliografías con grupos de investigación. Dada la proliferación de tales gestores bibliográficos, mencionaremos las ventajas de uno de ellos, de EndNote, ya que se trata del producto más utilizado en estos momentos (2012) por los investigadores españoles. Después de unas breves conclusiones presentamos la bibliografía.

\section{El arte de la citación}

La citación juega un papel central en un trabajo académico. Una citación es una recuperación, en el cuerpo de nuestro trabajo o en una nota, de las palabras de otros: ya se trate del texto-fuente que estamos analizando, o bien de un pasaje de la bibliografía secundaria. En líneas generales, la citación puede servir para lo siguiente: a) para presentar un texto (fuente primaria) que será luego analizado; en este caso, la citación puede ser larga; b) para recordar un argumento de un autor, en cuyo caso la citación debe ser corta; c) para simplemente definir un término; d) para apoyar mis argumentos; e) para criticar la teoría de un filósofo; f) para comparar afirmaciones de autores; g) etcétera. Ahora bien, puedo utilizar el texto original, las palabras textuales de la fuente, en cuyo caso tiene que ir entrecomillado, tal y como mandan las reglas de la tipografía española; o bien 
puedo utilizar una cita indirecta, parafraseando al autor, o cambiando parte del texto, y en este caso es imprescindible comunicar el origen de la fuente para que el lector pueda comparar o cotejar lo que hemos escrito o sugerido.

Las citas de otros autores se encierran entre comillas latinas ( «) o comillas inglesas (“”). Si son citas breves podemos colocarlas en el entramado textual, ya que no entorpecen la lectura. No obstante, si se trata de citas amplias, más de tres líneas, resulta conveniente sacarlas del entramado, colocar el texto en párrafo aparte, con un interlineado menor, o un tamaño de letra menor, o algún signo que indique que se trata de una cita. En este caso no se necesitan las comillas, y mucho menos, la cursiva; el lector ya entiende con ese gesto que se trata de una cita. Por supuesto, la entrada de la cita ha de incluir como antesala alguna expresión que la prepare - e.g.: a juicio de Hegel, según dice Bergson en su obra más significativa, tal y como argumenta Kant, el siguiente texto lo explica con claridad, el autor lo pone de manifiesto en un texto clave, y un largo etcétera. Ponemos a continuación en una especie de cuadro tres ejemplos, imaginando, en el primer caso, que la cita tiene extensión suficiente como para ir en párrafo aparte, y utilizando el Sistema Tradicional de citación, denominado así porque hasta ahora ha sido el más utilizado en España; también se le conoce como estilo o sistema humanístico, europeo, francés, tradición hispánica o cita-nota. De momento introducimos los datos manualmente, sin ayuda de gestores bibliográficos, de los que hablaremos en este capítulo. ${ }^{2}$

a. Son numerosos los autores que insisten en la necesidad de la lectura reposada y crítica. Bloom es uno de ellos:

La mejor forma de practicar la buena lectura es tomarla como una disciplina implícita; en última instancia, no hay más método que el propio, cuando uno mismo se ha moldeado a fondo ${ }^{1}$.

${ }^{1}$ Cómo leer y por qué. Barcelona: Anagrama, 2000, 13-14.

2 El Sistema Tradicional se fundamenta en la Norma ISO 690 y 690-2. Pueden consultarse, además del texto de las normas, numerosos documentos acerca de la aplicación de las dos normas, lo cual detallamos en la bibliografía final de este artículo. Un ejemplo: Universidad Carlos III de Madrid. Biblioteca. Cómo citar bibliografía: una guía de la Biblioteca de la Universidad de Carlos III de Madrid para estudiantes ante su Trabajo de Fin de Grado. [En línea y en pdf]. <http://www. uc3m.es/portal/page/portal/biblioteca/aprende_usar/como_citar_bibliografia $>$. [Consulta: $12 \mathrm{de}$ julio de 2012]. 
b. José Luis Villacañas analiza, en uno de sus últimos trabajos, la relación entre los juicios de valor y el saber científico, lo cual supone inevitablemente abordar la complejidad implicada en el problema de la racionalidad. El autor considera que «Weber pensaba que el académico no tiene títulos reales para decirle a la gente cuál es el valor absoluto». ${ }^{2}$

2 «El programa científico de Weber y su sentido hoy» [documento en pdf]. Ingenium. Revista Electrónica de Pensamiento Moderno y Metodología en Historia de la Ideas. [En línea]. Universidad Complutense de Madrid. Núm. 4, julio-diciembre 2010, p. 173. <http://revistas. ucm.es/index.php/INGE/article/view/INGE1010220167A/13751>. [Consulta: 12 de julio de 2012]. ${ }^{3}$

c. Existen muchas visiones acerca de lo que significa la filosofía. Es interesante la visión de Celia Amorós, cuando dice que «la filosofía es poner el mundo como la tesis de otro". ${ }^{3}$

${ }^{3}$ Pienso, luego existo. [serie de televisión]. Rtve a la carta. (0412-2011). 30:09. <http://www.rtve.es/alacarta/videos/pienso-luegoexisto/pienso-luego-existo-celia-amoros/1265475/>. [Consulta: 16 jul. 2012]. 1:01.

Con respecto al último ejemplo, interesa señalar que la Biblioteca de la Universidad Carlos III recomienda para programas de radio y televisión el siguiente orden de datos: Nombre del programa. Responsabilidad. Entidad emisora, fecha de emisión. Por su parte, Berthier nos indica el siguiente orden para series de televisión: nombre de la serie, número del episodio, nombre del episodio en cursivas (año de producción), lugar de realización, casa productora, fecha de transmisión [formato del soporte]. La mayoría de los expertos (y entidades como MLA y APA) coinciden en que los datos más importantes son el nombre del programa, la responsabilidad, la entidad emisora, y la fecha de emisión. Por coherencia gráfica con respecto al resto de fuentes de información documentales utilizados y presentados en una bibliografía, nuestra propuesta, en trabajos de investigación, y siempre y cuando se pueda personalizar la referenciación, es la siguiente: persona

${ }^{3}$ La norma ISO 690 recomienda escribir Disponible en: (Disponibilidad:, Disponible:, o En:) como antesala a la referenciación del sitio o URL. Consideramos que podemos obviar tal indicación ya que con las antilambdas $(<>)$ el lector ya comprende que se trata de la dirección correspondiente. Asimismo, la fecha de la consulta (siempre entre corchetes) puede abreviarse: [Consulta: 12 jul. 2012], o bien utilizar las expresiones: Fecha de consulta:, o Consultado: Martínez de Sousa, en su Manual de estilo de la lengua española (Gijón: Trea, 2001, pp. 95-97) opta, en los ejemplos, por la siguiente expresión: [Consulta: 12/07/2012]. En cualquiera de los casos es imprescindible seguir el mismo estilo. 
entrevistada, si es el caso, título de la serie o programa de televisión en cursiva, tipo de soporte entre corchetes, responsabilidad principal, fecha de emisión entre paréntesis, duración del programa (si es posible), disponibilidad y acceso (entre antilambdas), fecha de consulta entre corchetes, y lugar exacto de la cita verbal (si es posible y adecuado). ${ }^{4}$

Cada vez que hacemos referencia a un texto, o a un autor, cuando lo citamos, o simplemente cuando nos apoyamos en el trabajo de otros reformulándolo con nuestras propias palabras, es indispensable precisar, con gran escrupulosidad, el lugar exacto donde figura el texto o la opinión proporcionada. Si citamos explícitamente (entre comillas), debemos reenviar a las páginas exactas de la edición citada. Toda nota incompleta deja sobreentender que en realidad no hemos consultado la obra o el texto en cuestión, y que se trata de una referencia de segunda mano. Si nos apoyamos en un trabajo o documento en general, el título basta, seguido de la expresión pássim (por todas partes, en muchos lugares del documento, a lo largo de toda la obra). Si nuestra fuente consiste en una parte de una obra (por ejemplo un capítulo) también es necesario recoger la paginación correspondiente, o al menos el número del capítulo.

Las citas aparecen referenciadas como notas a pie de página o bien al final del capítulo o al final del trabajo. Ponemos, ya sea manualmente o con ayuda del gestor correspondiente, el nombre de pila y el apellido del autor, siempre y cuando no se haya citado en el entramado textual, aunque en lo sucesivo bastaría con el apellido, en minúscula; a continuación el título de la obra de la que hemos sacado la cita, utilizando la cursiva; y, por último, la zona de edición, es decir, ciudad, editorial, y año; el último elemento es el relativo a la página o páginas, omitiéndose la abreviatura de página o páginas (p., pp.), como suele ser ya costumbre en el mundo académico, siempre y cuando no exista riesgo de confusión. Si se trata de una cita indirecta, indicamos al lector que se dirija a una obra determinada para que pueda cotejar o comparar nuestras afirmaciones

4 cf. Cómocitarbibliografía.<http://www.uc3m.es/portal/page/portal/biblioteca/aprende_usar/ como_citar_bibliografia>. [Consulta: 15 de jul. de 2012]. Antonio Berthier. El sistema de Referencias Harvard. [documento en pdf]. <http:www.conocimientoysociedad.com/Harvard. html>. [Consulta: 16 jul. 2012]. 
con las auténticas palabras del autor de la cita; en este caso, la literatura sería la misma pero con la antesala de $c f$., que indica cotéjese, compárese, vaya a esa obra.

Teodoro de Andrés afirma que «La filosofía de Ockham se nos presenta dominada desde sus raíces por una opción primera diametralmente opuesta a la que está a la base de los grandes sistemas del siglo XIII». ${ }^{1}$

${ }^{1}$ El nominalismo de Guillermo de Ockham como filosofía del lenguaje. Madrid: Gredos, 1969, 27.

Con respecto al ejemplo anterior cabe advertir que una obra o documento puede tener más componentes en su asiento bibliográfico. En una nota a pie de página podemos omitir algunos de ellos, como la mención de todos los autores, si son más de dos, el subtítulo, o las responsabilidades secundarias, elementos que sí deben constar en el listado de Referencias bibliográficas, o Bibliografía. Asimismo conviene señalar que en la bibliografía este autor diría: ANDRÉS, Teodoro de; o bien, si hemos decidido abreviar todos los nombres: ANDRÉS, T. de.

Imaginemos que en la misma página citamos al mismo autor, la misma obra, pero diferente página; en ese caso utilizaríamos la abreviación de ibídem (ib., de cursiva), y la página nueva. Si hemos cambiado de página en nuestro trabajo, para evitar confusiones o carga de locuciones, podemos ir jugando, y emplear expresiones que guíen al lector: obra citada (ob. cit.); el título de la obra, y luego edición citada (ed. cit.); el apellido del autor y el título eventualmente abreviado (seguidos o no por tres puntos), si el título es una frase demasiado larga; op. cit. (abreviación de opere citato, obra citada) en el caso de una obra; art. cit. o loc. cit. (abreviación de artículo citado y loco citato, en el lugar citado) en el caso de un artículo; etc. Conviene recordar que la grafía ibid. se considera incorrecta.

ib., 60 .

Ob. cit., 68.

El nominalismo de Guillermo de Ockham como filosofía del lenguaje. Ed. cit., 90 .

En referencia al cuadro anterior conviene señalar que podríamos abreviar el título, advirtiendo de ello en la primera mención de la obra [En adelante El nominalismo de Guillermo de Ockham]. Asimismo podemos optar por un sistema de abreviaciones personal, o bien ya estandarizado académicamente, para designar las obras que 
citamos. En este caso es imprescindible colocar una lista al comienzo del trabajo, o bien en la bibliografía — e.g.: ST (Suma Teológica), DM (Discurso del Método).

Asimismo, la presentación de las notas reenviando a fuentes primarias puede obedecer a las mismas reglas que las detalladas en el punto precedente, pero contiene algunas variantes, que detallamos a continuación con algunas referencias — supuestamente en nota a pie de página.
${ }^{1}$ Aristóteles. Física. Madrid: Austral, 1990, 220.
${ }^{2}$ Descartes. Discurso del Método. Madrid: Bruguera, 1980, 40.
${ }^{3}$ Kant. Crítica de la Razón Pura. Madrid: Edaf, 2000, 25.

Estas últimas referencias bibliográficas no son muy explícitas, ya que nadie garantiza que nuestros lectores dispongan de la misma edición que estamos utilizando nosotros, y en consecuencia para algunos lectores puede ser dificultoso encontrar el pasaje citado. La única citación (y referenciación) correcta sería la que anotamos a continuación.

${ }^{1}$ Aristóteles. Física, VI, 2, 232a21 (trad. G.R. de Echandía, 220) [introducimos correctamente el libro y el capítulo, luego la numeración Bekker, y entre paréntesis la referencia a la traducción que hemos utilizado] ${ }^{5}$.

${ }^{2}$ Descartes. Discurso del Método, AT, VI, 25 (trad. R. Frondizi, 22) [introducimos la obra, y la notación de la edición de Adam y Tannery, el volumen, la página, y la traducción y página de la edición crítica traducida que hemos utilizado. También bastaría con: AT, VI, 25 (trad. R. Frondizi, 22)].

${ }^{3}$ Kant. Crítica de la Razón Pura, Ak., IV, B, 220 (trad. P. Ribas, 250) [damos así la numeración correspondiente a la edición original, la referencia a la Akademie-Ausgabe, y la referencia precisa de la traducción que hemos utilizado].

5 Se trata de una cita a pie de página. En la bibliografía tendríamos varias opciones, después de citar la obra canónica, es decir, la de Bekker. Por ejemplo: a) ARISTÓTELES. Física. Trad. y notas de G.R de Echandía. Madrid: RBA Gredos, 2007; b) ARISTÓTELES. Física. Madrid: Gredos, 1995. [Edición digital]. Trad. y notas de G.R de Echandía. <http://filologiaclasica.blogspot.com. es/2012/05/fisica-aristoteles-editorial-gredos.html\#!/2012/05/fisica-aristoteles-editorial-gredos. html>. [Consulta: 12 jul. 2012]. El mismo sistema utilizaríamos en el caso de Descartes y de Kant, si utilizamos ediciones en línea o CD-ROM o en formato pdf. El investigador tiene que estar alerta y utilizar las traducciones más reputadas por la comunidad científica. 
La cita que traemos al trabajo para su análisis debe guardar fidelidad al texto original, conservar su puntuación, e incluso sus posibles errores ortotipográficos. De esta regla quedan excluidos la negrita, el subrayado, o las mayúsculas, tipografías procedentes, la mayoría de las veces, de textos tipo diccionarios, y que tienen una finalidad que pierden al salir de su contexto. En cuanto a la fidelidad, si consideramos que el error contenido en una cita afecta a nuestro discurso, o pensamos que el lector puede confundirlo con un descuido nuestro, hay maneras para hacerlo saber. Vamos a poner un ejemplo. Tenemos un texto que dice que «Darwin publicó El origen de las especies en 1459». Pues bien, con un sic entre corchetes y cursiva bastaría para el lector entendiera que se trata de un error de escritura: "Darwin publicó El origen de las especies en 1459 [sic]». Sin embargo si nos topamos con un texto que dice que «Hegel comunicó su doctrina en su gran obra titulada El ser y la esencia», no basta un simple sic. Dependiendo de la gravedad del error podríamos, o bien escribir: «Hegel comunicó su doctrina en su gran obra titulada El ser y la esencia [sic, fue Gilson quien compuso esta obra, y no Hegel]», o bien poner una nota a pie de página aludiendo al error y a su posible origen.

Supongamos que estamos leyendo la obra titulada La unidad de la experiencia filosófica, de Etienne Gilson, y en dicha obra, en la página 272, hemos encontrado una cita de Rousseau que nos interesa mucho para afianzar cierto argumento. La cita, en este caso corta, dice: " $i \mathrm{Oh}$ conciencia, conciencia, instinto divino..., infalible juez del bien y del mal!». Pues bien, nuestra cita a pie de página constaría de toda la referencia bibliográfica que recoge a pie de página Gilson, más una adenda por nuestra parte que se refiere al intermediario, con la locución apud, que indica en casa de.

Las siguientes palabras son significativas y reflejan una constante en la vida: « $\mathrm{O}$ h conciencia, conciencia, instinto divino..., infalible juez del bien y del mal!». ${ }^{1}$

1 J. J. Rousseau. Profession of Faith of a Savoyard Vicar. Trad. O. Schreiner. Nueva York, 1889, 64. Apud [o también: APUD] E.Gilson. La unidad de la experiencia filosófica. Trad. Carlos Amable Baliñas Fernández. Madrid: Rialp, 1960, 272.

Otra de las preguntas que podríamos hacernos es cómo comunicamos al lector que hemos omitido parte del texto de origen, ya que no nos interesaba todo el párrafo sino simplemente dos o tres frases, o bien cómo puedo introducirme 
en el texto sin el permiso del autor, sin alterarlo lo más mínimo, y que el lector lo entienda. Pues bien, para ello tenemos que emplear los corchetes, y nunca los paréntesis. Si quisiéramos eliminar varias palabras del texto original pondríamos corchetes intrapuntuados, los cuales también sirven para indicar que la frase que hemos entresacado empieza con minúscula, o bien para poner de cursiva lo que en el texto va de redondo. Ponemos a continuación un ejemplo.

Ángel González Álvarez afirma en una de sus obras lo siguiente:

«La analogía del ente no puede ser puramente extrínseca. Todos los modos del ente son formal e intrínsecamente pertenecientes al ente. [...] Si la entidad no se encuentra realizada en las cosas, no hay cosas, y su realidad se esfumaría en la nada [la cursiva es mía]».'

${ }^{1}$ Tratado de Metafisica: ontología. Madrid: Gredos, 1967, 182.

González insiste y aduce que « [...] diríamos que Cayetano y Suárez estaban de acuerdo en la modalidad intrínseca de la analogía metafísica». ${ }^{2}$

2ib., 183.

Cabe preguntarse en qué lengua vamos a citar. Pues bien, en principio, toda citación debe registrarse en español, para facilitar la lectura continuada del texto y también probar que comprendemos lo que citamos. Si citamos un texto-fuente cuyo original está en una lengua distinta que el español, es aconsejable, en la medida de lo posible, localizar y mencionar el texto original correspondiente en una nota, e indicar siempre cuidadosamente quien es el traductor. Algunos expertos recomiendan conservar los títulos en lengua original — salvo para los textos griegos, donde se adoptará la abreviación latina o la retranscripción española más corriente. Si no mencionamos ningún traductor, se partirá del principio de que somos nosotros quienes lo hemos traducido, y que si existe un error o imprecisión, somos nosotros los responsables. En el caso de la literatura secundaria en lengua extranjera (alemán, francés, inglés, etc.) si citamos solamente en nota, es preferible dejar el texto en lengua original. Si citamos en el cuerpo del texto, es conveniente traducir el texto al español.

El arte de la citación varía en función de los casos, en particular según que se trate de una fuente primaria (el texto que estamos analizando) o de una fuente secundaria (un comentador). En el caso de las citaciones de fuentes primarias, a veces podemos vernos obligados a citar un pasaje extenso del autor que estamos 
estudiando: en este caso, después de la citación, no es conveniente pasar sin ninguna forma de proceso a otra cosa. Una citación es siempre el comienzo de un análisis, y la cita, en principio, no habla por sí misma: también es conveniente descifrar los diferentes elementos del texto citado, explicar su estructura, definir los términos, etc. Toda citación extensa necesita un análisis pormenorizado por nuestra parte.

En cuanto a la citación de fuentes secundarias, lo más aconsejable y enriquecedor consiste en leer a los filósofos, y no a los comentadores. Se supone que un trabajo académico se apoya sobre fuentes primarias, y no secundarias. En consecuencia, intentemos no abusar de citaciones en materia de fuentes secundarias. Asimismo, no olvidemos que existen numerosos documentos que no conviene citar nunca: documentos sin indicación de autor encontrados en internet, enciclopedias o diccionarios generales (el Larousse; la enciclopedia Encarta de Microsoft, wikipedia, etc.). Podemos citar diccionarios o enciclopedias, pero siempre y cuando se trate de diccionarios especializados, y su citación debe estar plenamente justificada -e.g.: Diccionario de Filosofía, Vocabulario Filosófico, y en estos casos siempre hay que mencionar al autor de la fuente: Ferrater Mora, Lalande.

Ofrecemos a continuación algunas recomendaciones.

En primer lugar, es conveniente evitar los ib. op. cit., etc., y preferir un sistema de abreviación previamente definido y explicado en la introducción, o bien en la bibliografía. El título completo y las referencias exactas de la edición deben figurar en la bibliografía.

Segundo, es preferible conservar los nombres latinos de los autores clásicos o medievales (aunque no sea obligatorio).

En tercer lugar, resulta beneficioso indicar las subdivisiones del texto de origen (libro, cuestión, distinción, artículo, etc.). Por ejemplo, para Aristóteles se necesita incluir la numeración del pasaje conforme a la numeración llamada Bekker, que se refiere a la edición monumental realizada por el erudito alemán August Immanuel Bekker (1785-1871) (Aristotelis Opera. 11 vols. Berlin: Akademie der Wissenschaften, 1831-1876). La numeración Bekker está compuesta de hasta cuatro cifras, de una letra ( $\mathrm{o}$ o b) para la columna, y de un número de línea. Así, el comienzo de la Ética a Nicómaco es 1094a1: es decir página 1094 de la edición Bekker, columna a, línea 1. El mismo sistema existe para Platón, pero es más antiguo: se trata de la numeración que se remonta a la edición de las obras de Platón por Henri Etienne (Stephanus) en 1578. Es menos precisa: cada 
número responde a una sección que comprende varios parágrafos o párrafos de los diálogos socráticos, divididos en partes A, B, C, D y E: así, Simposion 172A corresponde a la página 172 en su primer párrafo, la obertura del Banquete.

En cuarto lugar, hay que tener en cuenta que para los autores disponibles en las ediciones canónicas, es imprescindible dar la paginación precisa de las ediciones de referencia: edición Adam-Tannery (AT) para Descartes; AkademieAusgabe (Ak) para Leibniz o Kant; Gesamtausgabe (GA) para Heidegger; Husserliana (Hua) para Husserl; Hermann Diels-Walther Kranz. Die Fragmente der Vorsokratiker (DK), para los Presocráticos; Opera Theologica, para Juan Duns Escoto o Guillermo de Ockham (OTh); Patrologia Graeca, ed. J.P.Migne (PG), para la Patrística griega; Patrologia latina, ed. J.-P. Migne (PL), para la Patrística latina; etc. Esto da testimonio de que sabemos orientarnos en estas ediciones. En principio, esta serie de abreviaciones de colecciones célebres no necesitan ser aclaradas, ya que son del dominio común en el campo de la historia de la filosofía.

Por último, no hay que olvidar que siempre hay que comunicar al lector la traducción utilizada. Aunque parezca un rasgo sin importancia no es lo mismo una traducción que otra. Por ejemplo, estamos elaborando un trabajo sobre Kant y su obra filosófica más influyente, la Crítica de la razón pura. Pues bien, manejar la traducción de Pedro Ribas, docente de la Universidad Autónoma de Madrid, es imprescindible. La editorial Taurus, en el año 2005, recupera la edición de Alfaguara (1997: 13. a edición), considerada académicamente como la mejor edición de esa obra de Kant. En esta edición nos encontramos con una traducción que ha utilizado el texto de la primera edición con las modificaciones que introdujo el propio Kant en la segunda, indicando en cada caso de qué edición se trata y ofreciendo en el margen la paginación correspondiente de ambas ediciones. Asimismo la edición de Ribas se completa con una exhaustiva introducción que incluye información detallada sobre la vida de Kant y sobre la obra, así como una cronología y una bibliografía muy útiles para el estudio del filósofo alemán. Ahora bien, tampoco podemos rechazar la edición bilingüe que nos ofrece la editorial Fondo de Cultura Económica, aparecida en el año 2009. Esta nueva edición de la Crítica de la razón pura, se debe a Mario Caimi, docente de filosofía en la Universidad de Maguncia, considerado como uno de los más renombrados investigadores actuales de la filosofía de Kant. Además, Caimi recibió el Premio Kant Internacional 2010, otorgado por la Sociedad Kant y la Fundación Fritz Thyssen, siendo traductor de la Crítica de la razón pura, y ofreciendo un valioso estudio preliminar así como un variado aparato de notas. Otro importante documento es la edición abreviada, introducción, notas y anexos de Juan José García 
Norro y Rogelio Rovira (con la traducción de Manuel García Morente), de la Crítica de la razón pura (Madrid: Tecnos, 2004), edición que presenta una valiosa introducción biográfico-crítica para preparar al lector a la mejor comprensión y valoración de esta obra cumbre del pensamiento occidental. Se completa con un apéndice final con glosario, biografías y bibliografía referenciada a la obra.

\section{Sistema MLA y Sistema Tradicional}

Hasta ahora nos hemos referido a la citación y referenciación de un estilo bibliográfico, el Tradicional, en forma manual. Más adelante hablaremos de los gestores que nos pueden ayudar a agilizar informáticamente esta labor, a veces pesada y laboriosa. Tal y como hemos indicado, la normativa que sigue el Sistema Tradicional es la norma ISO 690-1987 — y su equivalente en España, la norma UNE 50-104-94- Referencias bibliográficas: contenido, forma y estructura. Estas reglas establecen los criterios para la elaboración de citas y referencias bibliográficas de documentos textuales. Por otra parte la norma ISO 690-2 especifica los elementos que debemos incluir en las citas bibliográficas de los documentos electrónicos. A decir verdad, la norma ISO 690 (1 y 2) indica las zonas obligatorias y el orden de las mismas pero no prescriben la puntuación que las separa o el estilo tipográfico. No obstante la puntuación y la tipografía se pueden deducir de los ejemplos que se exponen en la norma. ${ }^{6}$

Pues bien, la confección de citas y bibliografía en el Sistema MLA — creado por la Modern Language Association- presenta ligeras variantes de puntuación y tipografía con respecto al Sistema tradicional. ${ }^{7}$ No obstante podemos adaptarlo a nuestra ortotipografía. Apuntamos a continuación algunos datos a tener en cuenta:

a) el apellido del autor se escribe en minúsculas (como en el Sistema Harvard y en el Sistema APA), lo cual es correcto cuando se trata de una

${ }^{6}$ Existen tres ediciones de la norma ISO 690: a) ISO 690:1975; b) ISO 690:1987 (Documentación. Referencias bibliográficas. Contenido, forma y estructura). La Asociación Española de Normalización y Certificación tradujo y adaptó al español este documento como UNE 50-104-94. Como complemento de la anterior, se publicó la ISO 690-2:1997 (Información $y$ documentación. Referencias bibliográficas. 2. ${ }^{a}$ parte: Documentos electrónicos o fragmentos); c) ISO 690:2010. Information and documentation. Guidelines for bibliographic references and citations to information resources, que es la edición actual y que reemplaza a la anterior y su complemento.

7 cf. Joseph Gibaldi. MLA Handbook for Writers of Research Papers. $7^{\text {th }}$ edition. New York: Modern Language Association of America, 2009. 
cita a pie de página ya que no se trata de una bibliografía académica; no obstante, en la bibliografía podemos colocarlo en mayúscula, tal y como recomienda ISO 690.

b) se abrevia el nombre de pila sin punto abreviativo, requisito de la Real Academia para la abreviación que tendríamos que corregir;

c) no pone de cursiva el título de una monografía sino que utiliza el subrayado, detalle que podríamos cambiar;

d) no coloca coma detrás de la fecha de publicación, sino un espacio, coma que colocaríamos sin problema;

e) no entrecomilla el título de un artículo de publicación periódica, y subraya el título de la revista. Nosotros pondríamos comillas en el título y cursiva en el título de la revista.

f) las comillas que utiliza MLA son las comillas mecanográficas y no las inglesas o las latinas, aspecto que podemos modificar.

Pongamos un ejemplo de cita de una monografía en el entramado textual y en una bibliografía, siguiendo el sistema MLA y nuestra adaptación a ese sistema:

\section{MLA citación}

a) Según nos advierten algunos expertos, los recursos de Internet son tan vastos y variados que usted debe ser muy selectivo acerca de cuáles utilizará para una investigación académica (Walter 39).

b) Según nos advierte Walker, los recursos de Internet son tan vastos y variados que usted debe ser muy selectivo acerca de cuáles utilizará para una investigación académica (39).

Modificación citación

a) Según nos advierten algunos expertos «los recursos de Internet son tan vastos y variados que usted debe ser muy selectivo acerca de cuáles utilizará para una investigación académica» (Walter: 39). 
b) Según nos advierte Walker «los recursos de Internet son tan vastos y variados que usted debe ser muy selectivo acerca de cuáles utilizará para una investigación académica» (39).

MLA bibliografía

Walker, Melissa. Cómo escribir trabajos de investigación. Barcelona, Gedisa, 2000 .

Modificación bibliografía

WALKER, Melissa. Cómo escribir trabajos de investigación. Barcelona: Gedisa, 2000.

\section{Implementación del Sistema Harvard o APA en el ámbito de la filosofía}

Hasta ahora hemos empleado el Sistema Tradicional (y el Sistema MLA) en todos los ejemplos, sistema con una larga tradición académica en el campo humanístico y filosófico. Para algunos intelectuales y profesores goza de buena salud porque tiene numerosas ventajas. En primer lugar, usando este estilo humanístico podemos utilizar una gama muy amplia de locuciones latinas y de abreviaturas de gran tradición filosófica que enriquecen el escrito y le confieren un aspecto elegante y a veces suntuoso. Por ejemplo: infra, supra, idem, ibidem, apud, opus citatum, confers, nota bene, pace, pássim, quod vide, locus citatum, y un largo etcétera.

En segundo lugar, con el sistema europeo el trabajo presenta un nivel más alto de fidelidad a las fuentes que con el sistema Harvard. En efecto, el autor cita con minuciosidad la obra de la que ha extraído el texto, el cual se presenta entre comillas latinas o con otros distintivos, o bien remite al lector a los documentos que han inspirado sus argumentos o críticas. Estos aspectos aportan al trabajo rigor científico y utilidad para futuras investigaciones. Sin embargo, en el Sistema Harvard no siempre se respeta esta escrupulosidad científica y a veces el lector no está seguro si se trata de una cita literal o de una cita indirecta o de una inspiración, ya que el texto no presenta diacrisis tipográfica clara ni tampoco aparecen las páginas de la obra de la que supuestamente se ha sacado esa supuesta cita; solo se indica el autor y la obra. 
La principal desventaja del sistema humanístico deriva del abuso, a pie de página, de las locuciones latinas para indicar al lector los documentos y las páginas que apoyan el trabajo, produciéndose confusiones y paradas constantes en la lectura. Se habla incluso del efecto cereza, por el continuo goteo de indicaciones a las fuentes de consulta. También supone una desventaja la unión de citas y de notas, lo cual recarga innecesariamente algunas investigaciones, dándoles una falsa apariencia de erudición.

Estas y otras muchas razones han llevado a la implementación del Sistema Harvard, sistema que recibe diferentes denominaciones: autor-año, Sistema APA, estilo Chicago, Sistema americano, estilo anglosajón, estilo Turabian, etc. En efecto, el sistema de citación que numerosos investigadores y editoriales eligen para la presentación de los originales es el sistema de autor-año, sistema muy recomendado por determinados manuales de estilo de las universidades americanas o de ámbito anglosajón, sobre todo para la mayoría de las ciencias sociales y las ciencias naturales, si bien ya se ha impuesto en el campo de las ciencias humanas y de la filosofía, sobre todo por la distinción que permite entre citas, notas y referencias bibliográficas. ${ }^{8}$

Pues bien, es importante tener presente la adaptación en España del sistema Harvard, adaptación que puede conseguirse manualmente o modificando algunos parámetros del gestor bibliográfico elegido, lo cual supone, principalmente algunos matices diacríticos y tipográficos; por ejemplo: a) colocar coma entre el apellido y la fecha en vez de un simple espacio; b) dos puntos entre la fecha y la paginación, en sustitución de la coma, que a veces produce confusión; especificar conferir, en su abreviación ( $c f$.), si no se trata de cita literal, lo cual aclara al lector acerca de la intencionalidad de la cita; c) el uso de las locuciones o sus abreviaciones de idem, ibidem, infra, supra, apud o pássim, cuando así lo exija la investigación (id., ib., infr., supr., ap., páss.); d) sin embargo, se mantiene la omisión de la abreviatura $p$. (de página), como ya es habitual en la producción científica internacional, aunque el APA conserva dicha abreviación en citas literales.

En el Sistema Harvard, con las varias ortotipográficas mencionadas, las fuentes se citan en el entramado textual del manuscrito, entre paréntesis, por el

8 El sitio web oficial del Estilo APA, <http://www.apastyle.org>, contiene valiosa información sobre las últimas actualizaciones del estilo APA y las diferencias y ventajas entre ellas. La sexta edición en inglés es del año 2010. Asimismo puede ser útil consultar el tutorial sobre el estilo APA, el cual brinda múltiples ejemplos: <http:www.apastyle.org/learn/index.aspx>. 
primer apellido, coma (,), año de publicación, dos puntos (:) página o páginas correspondientes a la cita textual. Si el apellido del autor ya ha sido mencionado, en el paréntesis figurará el año de publicación del documento y la página o páginas, si corresponde. Cuando se trata de un autor con dos o más obras publicadas en el mismo año, éstas se distinguirán con letras en minúscula y en cursiva junto al año $(a, b, c \ldots)$. En el que caso de que la fuente sea de dos autores, se citan sus primeros apellidos unidos por $y$; si se trata de más de dos, se puede optar por citar el primer apellido, seguido de la expresión et al., en cursiva o letra grifada, aunque el APA y la MLA omiten tal diacrisis y lo escriben con letra redonda. Todo este sistema de citación tiene, evidentemente, una correspondencia particular y rígida con el listado de referencias bibliográficas o en la bibliografía. Veamos un ejemplo.

Algunos autores están convencidos de que «la investigación científica es esencialmente una labor intelectual que exige conocer y aplicar las técnicas existentes referentes al ejercicio de la inteligencia y a la creatividad» (Sierra, 1999: 16).

Conviene insistir en que «cada disciplina académica posee su propio método para organizar el conocimiento, y las formas específicas en que se debe escribir para cada área de conocimiento son parte inherente de la propia disciplina» (Creme y Lea, 2000: 13).

Determinados especialistas consideran que «la mejor manera de disciplinar a los autores es ofreciendo ejemplos en las instrucciones a autores de cómo se elabora una referencia para cada tipo documental a referenciar» (Delgado et al., 2003: 75).

Este sistema de citación, como hemos advertido, necesita tener su correspondencia en el listado de Referencias bibliográficas (o Bibliografía). Destacamos algunos detalles particulares del APA (o Harvard): a) el apellido se escribe en minúsculas, y lo modificaríamos a mayúsculas o versalitas; b) en ocasiones el año de publicación no va entre paréntesis, y nosotros conservaríamos el paréntesis; c) no se utiliza la cursiva para destacar el título de la monografía, aunque a veces va subrayado, conservando nosotros la cursiva; d) las responsabilidades secundarias se citan después del título (y su punto) entre paréntesis, y nosotros quitaríamos el paréntesis; e) el conector que une una parte de la obra con la obra global (En: o In: ) va todo en mayúsculas (EN: o IN: ), y nosotros optaríamos por En: f) el lugar de edición y el nombre de la editorial se separan por una coma, y nosotros utilizaremos los dos puntos. Por supuesto, estos detalles pueden incorporarse al 
gestor bibliográfico. La información quedaría, para los ejemplos propuestos, y realizadas las modificaciones pertinentes, reflejada en el cuadro siguiente.

CREME, P.; LEA, M.R. (2000). Escribir en la universidad. Traducción de G. Ventureira. Barcelona: Gedisa.

DELGADO LÓPEZ-CÓZAR, E.; RUIZ PÉREZ, R.; JIMÉNEZ CONTRERAS, E. (2003). Informe de evaluación de las revistas cientificas editadas por el servicio de publicaciones de la Universidad Complutense de Madrid. Granada: Grupo de Investigación, Evaluación de la Ciencia y de la Comunicación Científica@.

MARTÍNEZ DE SOUSA, J. (2000). «Las referencias bibliográficas y las bibliografías». En: MARTÍNEZ DE SOUSA, J. (2000). Manual de estilo de la lengua española. Gijón (Asturias): Trea, 74-97.

SIERRA BRAVO, R. (1999). Tesis doctorales y trabajos de investigación cientifica: metodología general de su elaboración y documentación. 5. ${ }^{\text {a }}$ ed. Madrid: Paraninfo.

UNIVERSITY OF ILLINOIS. (1997). Bibliography styles handbook. [En línea]. <http://www.english.uiuc.edu/cws/wworkshop/bibliostiles. htm>. (28-10-1997). [Consulta: 17 jul. 2012].

Pues bien, este sistema proporciona a los filósofos y a los escritores algunos beneficios que no se pueden pasar por alto. En primer lugar hay que señalar que se trata de un sistema dinámico, práctico, ergonómico, claro y de fácil aplicación. Las ventajas que ofrece para el autor y para el lector son numerosas: permite ańadir, mover y eliminar citas en el texto sin que nos veamos obligados a recomponer inmediatamente la lista de referencias o las notas; añadir, mover o eliminar una cita significa la renumeración automática o manual de todas las llamadas y sus correspondencias en la lista de referencias. Para el lector tiene también ventajas: frecuentemente la indicación de autor y ańo de un trabajo pueden bastar a los especialistas para identificar una obra; se evitaría así el engorro de consultar reiteradamente la lista de referencias. Incluso para los lectores no especialmente familiarizados con la literatura citada, la inserción de los años en las citas les puede transmitir una cierta perspectiva histórica sobre el desarrollo de los conceptos, técnicas, métodos y descubrimientos comunicados en los trabajos.

Hay que poner de manifiesto que para los investigadores en el campo de la filosofía, la principal ventaja que tiene el Sistema Harvard (o el APA) consiste en el uso diferenciado entre citas textuales y notas, lo cual permite al autor y al 
lector hacer un uso selectivo de las notas o posponer la lectura de las mismas, además de que se enriquece enormemente la investigación científica.

Por otra parte, este sistema es más económico en espacio y en tiempo, ya sea para el autor, el editor o el compositor, ya que en el Sistema Tradicional o humanístico es necesario repetir en nota, a pie de página o al final del documento, los principales elementos de la cita bibliográfica. También ahorra coste a la editorial y al público. Además, proporciona una mejor y más amplia visibilidad a los autores, en tanto en cuanto sus nombres figuran en el entramado textual principal del trabajo, y no en cuerpo menor a pie de página, pudiéndose así ser objeto de una reiterada lectura.

Ahora bien, se impone hacer tres precisiones. En primer lugar, la comunidad científica debe prestar atención cuando use el Sistema Harvard, de procedencia anglosajona, adaptando la puntuación y la ortografía a la normativa española, cuando se hace una investigación en español. En segundo lugar, es preciso indicar que no todas las disciplinas deben sentirse obligadas a utilizar este sistema ya que, por ejemplo, las ciencias humanas, por su tradición y por su campo de estudio, se ajustan en mayor medida al Sistema Tradicional, por el juego de locuciones latinas, de guińos al lector, de remisiones constantes a distintas partes del trabajo, por la cantidad de información proporcionada, por el empleo de distintas diacrisis tipográficas, etc. Todo ello proporciona una estética y un marco de referencia difícilmente alcanzable siguiendo el Sistema Harvard. Por último, es conveniente mencionar que la principal desventaja del Sistema Harvard es que sobrecarga el texto y puede dificultar la lectura del mismo, sobre todo cuando se necesitan citar varios documentos al mismo tiempo. Esto sucede de forma constante en los artículos de revisión y en todos aquellos documentos que están repletos de declaraciones sumarias que recogen o sintetizan las aportaciones de diversos trabajos. Hay que señalar que esto ocurre también en disciplinas en las que se da un mayor volumen de producción científica, o donde los avances en el conocimiento solicitan la replicación inmediata y constante de los hallazgos obtenidos, como por ejemplo, el campo de la Biomedicina. El Sistema Harvard, en consecuencia, no sería aconsejable en ese tipo de campo temático.

\section{Las notas y las remisiones}

Se llaman notas a las pequeñas aclaraciones, anotaciones, indicaciones, llamadas de atención, explicaciones o digresiones, útiles para la perfecta comprensión 
del trabajo que hemos redactado, pero que no pertenecen directamente al desarrollo del discurso conceptual, sino que más bien lo entorpecen de alguna manera.

La función que tienen las notas en un trabajo académico es muy importante. A veces, citas y notas se usan como sinónimos, pero son elementos del trabajo que presentan ciertas diferencias; en ambos casos, ciertamente, acompañan a un texto, aun cuando siempre se sitúan fuera de él.

A decir verdad, las notas a pie de página tienen una larga historia, como lo ha revelado el historiador americano Anthony Grafton en una obra significativa, Los orígenes trágicos de la erudición, en la que considera que «Una serie de polémicas sobre notas al pie revela el uso - y abuso- que sufren en manos de ciertos polemistas: generalmente les sirven para acusar al adversario de incompetencia en lugar de responder a sus argumentos». ${ }^{\text {? }}$

Las notas pueden ser de índole muy diversa y variada: un dato bibliográfico, una referencia histórica, una aclaración etimológica, las palabras textuales en una lengua extrańa. Pueden ser necesarias, por ejemplo, para abrir nuevos frentes de análisis; también sirven para remitir al lector a otras fuentes que tratan con más amplitud el tema; en ocasiones sirven para incluir una cita curiosa que no halla lugar en el texto, debido a la contextura del mismo. Asimismo, pueden utilizarse para situar a pie de página la traducción o la adaptación de un texto extranjero que se ha traído como cita; en el entramado textual no cabe admitir más lengua que aquella en que se redacta el trabajo, si bien, en algunos casos se permite algún pequeño texto en latín, o en griego. Por último, pueden usarse para expresar algún agradecimiento por la ayuda que en aquel punto concreto de la investigación ha prestado un organismo o una persona particular, o un autor o documento relevante.

No conviene olvidar que las notas nunca se ponen por una ostentación de erudición, ni para adornar, ni para dar cabida a lo que por algún descuido o falta de habilidad no hemos colocado en el texto. Únicamente resultan adecuadas en razón de necesidad o de utilidad para que el texto se entienda mejor, o para ofrecer campo de abono a investigaciones futuras.

En todos estos casos la nota nos sirve a nosotros para reencontrar la fuente o el origen de un argumento, y permite también al lector verificar nuestras afirma-

9 México[Etc.]: FCE, 1998, p. 20. 
ciones. Es conveniente tener presente que lo que nosotros escribimos interesa a los profesores-lectores, que quizá quieran en ocasiones verificar lo que decimos, o leer el texto que hemos sacado de su contexto.

Por otro lado, nos encontramos con las remisiones, que pueden definirse como aquellas indicaciones que se sitúan en un lugar de un texto con la finalidad de que el lector acuda a un punto concreto del propio trabajo (remisión interna), o vaya a otro documento (remisión externa) para poder así confirmar una aseveración, un argumento o, simplemente, una ampliación de la materia.

Los signos para indicar las remisiones internas son una serie de locuciones y abreviaturas, como v., n.b., q.v., supra, infra, v.t., v.a., las cuales se colocan a pie de página, y van en minúscula, a pesar de que empiecen la frase. Las remisiones externas, se expresan generalmente con la abreviatura de conferir ( $c f:$ confróntese, cotéjese) o de comparar (cp.: compárese).

$v$. (vide): véase; $n . b$. (nota bene): fíjese bien; q.v. (quod vide): véase; supra: vaya más arriba; infra: vaya más abajo; v.t.: véase también; v.a.: véase además.

Asimismo, es muy aconsejable evitar las remisiones genéricas, a ningún lugar, a ninguna parte, como aquellas que dicen véase anteriormente, o véase más adelante, casos, además, en los que debe emplearse la palabra entera, y no la abreviatura (dado que no le sigue dato numérico); este tipo de indicaciones no sirven ya que el lector no sabe adónde dirigirse. El problema se agrava si se utilizan formas como supra o infra, o fórmulas que, aunque correctas, son rechazables, como: más arriba o más abajo.

Otro de los aspectos es el referente a la remisión a partes, capítulos, subcapítulos, apartados o párrafos, situación en los que la grafía va a depender del tipo de numeración. Por ejemplo, si estamos utilizando la numeración decimal, y se tienen cuatro órdenes, uno de capítulos, otro de subcapítulos, otro de apartados y otro de subapartados, la disposición de los distintos elementos sería la que se recoge en el siguiente cuadro.

$$
\text { cf. } 2.3-4 b \text {. }
$$


Lo anterior indica: confróntese el subapartado b del apartado 4 del subcapitulo 2.3. No olvidemos que la letra del apartado, subapartado o párrafo, según correspon$\mathrm{da}$, tiene que componerse de cursiva y puede ir pegada al número anterior, o separarse con espacio: $4 b$, o con coma y espacio: $4, b$.

\section{Presentación y estructura de las Referencias bibliográficas y de la Bibliografía}

Podemos optar por un listado de Referencias bibliográficas o por una Bibliografía. A pesar de que parezcan sinónimos, se trata de apartados distintos, ya que las Referencias bibliográficas recogen todos los documentos que han sido mencionados a lo largo del trabajo, y su presentación no requiere una regla muy estricta; podemos presentarlas por orden alfabético, por orden de aparición, en varios bloques temáticos, por capítulos, etc. Sin embargo, la Bibliografía sí que obedece a reglas muy estrictas, no sólo formales, sino también conceptuales. Por ejemplo, la Bibliografía recopila no sólo los documentos que se han utilizado para elaborar el trabajo, sino también todas aquellas fuentes que consideramos pertinentes para la mejor comprensión del tema, aun cuando no se hayan mencionado, ni a veces utilizado; además, se escribe en párrafo francés, por orden alfabético, con el apellido en mayúsculas (o versalitas), y otras consideraciones que pondremos de relieve en este apartado. Ahora bien, dado que en muchas ocasiones se confunden Referencias bibliográficas con Bibliografía, vamos a optar por la denominación de Bibliografía, aunque solamente recojamos las referencias bibliográficas.

Pues bien la regla principal en cuanto a lo que se precisa incluir en la Bibliografía es muy simple: todo texto, documento, fuente impresa o electrónica, citados en el trabajo, debe imperativamente figurar en la Bibliografía. Aunque estemos muy tentados a ello, hoy en día no sirve para nada hacer una larga lista de títulos que no han pasado por nuestras manos ni por nuestros ojos. Existen numerosos modelos de Bibliografía diferentes, en función de disciplinas, modas, países o universidades. Aquí vamos a recomendar el Sistema Tradicional (o sistema continental clásico) y el Sistema Harvard (o APA). En ambos sistemas se estructura la Bibliografía en dos secciones o partes, claramente diferenciadas: una primera dedicada a las fuentes primarias, y otra donde se recogen las fuentes secundarias; y no es conveniente mezclar todos los títulos en una sola lista. Esta estructura puede ser manual o mediante el gestor bibliográfico elegido. 
Entre las fuentes primarias figuran todas las obras, artículos o textos del autor o de los autores que hemos elegido para estudiar, así como otras fuentes primarias que hemos discutido a lo largo de nuestro trabajo. En general, todo autor anterior a 1850 merece figurar en el rótulo de fuente primaria. Después de esta fecha la cosa se complica, y va a depender de nosotros quién merece figurar en la parte de fuente primaria, y quién en la secundaria. Por ejemplo, algunos autores consideran a Heidegger como una fuente secundaria si estamos elaborando un trabajo sobre Platón; otros prefieren clasificarlo de fuente primaria. Incluso si nuestro trabajo se basa en un filósofo actual, como podría ser Deleuze, Derrida, o Nancy, estos serán entonces nuestras fuentes primarias; en cambio, los estudios sobre Deleuze, Derrida o Nancy serán para nosotros fuentes secundarias. En este apartado de fuentes primarias hay que tener en cuenta algunos detalles, que mencionamos a continuación.

Primero: es habitual usar el nombre latino de los autores antiguos o medievales (e.gr.: Tomás de Aquino, Duns Escoto). Segundo: según una regla de biblioteconomía todos los autores anteriores a 1500 son clasificados alfabéticamente por su nombre; los posteriores a 1500 son clasificados por su nombre de familia - e.gr.: Duns Escoto debe ser registrado por Juan Duns Escoto, y Tomás de Aquino por Tomas; Francisco Suárez por el contrario por la S (Suárez, Francisco)—. En tercer lugar, todas las fuentes primarias citadas deben serlo según su edición crítica de referencia — si existe, claro está-, así como todas las traducciones utilizadas, con todas las referencias exactas, en particular la indicación del nombre del traductor.

Ponemos a continuación un ejemplo que ilustre este apartado de fuentes primarias. Imaginemos que nuestro trabajo tiene como fuentes principales a) la Física de Aristóteles, utilizando la traducción de G.R. de Echandía; b) la Crítica de la Razón Pura de Kant, y hemos utilizado la traducción de P.Ribas; y c) dos obras de Descartes, Reglas para la dirección del espiritu, y Discurso del método, y hemos utilizado la traducción de J.M. Navarro Cordón y la traducción de R. Frondizi, respectivamente. Pues bien, pondríamos en primer lugar la obra considerada como canónica de Aristóteles, Kant, y Descartes, y después la traducción utilizada. Por ejemplo, en el caso de la primera obra de Descartes mencionada, su nomenclatura clásica es AT, X, que significa edición de Adam y Tannery, volumen $\mathrm{X}$; y después colocaríamos la edición crítica y traducción que hemos utilizado. Por supuesto, estas referencias tienen su correspondencia en la citación de las 
mismas a lo largo del trabajo, dejando constancia de la obra fuente y de la traducción que hemos utilizado. ${ }^{10}$

ARISTÓTELES. Naturalis Libri Auscultationis VIII. En: Aristotelis Opera. Edición de A. I. Bekker. 11 vols. Berlín: Akademie der Wissenschaften, 1831-1876, vol. 2.

- Física. Introducción, traducción y notas de G.R. de Echandía. Barcelona: RBA Gredos, 2007.

KANT, I. Kirtik der reinen Vernunft. En: KANT, I. Inmanuel Kant Gesammelte Schriften. Herausgegeben von der Preussische, bzw. 28 vols. Berlin: Von der Deutschen Akademi der Wissenschaften, 1902-1979, vol. IV [KrV, IV].

- Crítica de la razón pura. Prólogo, traducción, notas e índices de P. Ribas. Madrid: Taurus, 2005.

DESCARTES, R. Regulae ad directionen ingenii. En: DESCARTES, R. Oeuvres complètes. 13 vols. Ed. de Ch. Adam y P.Tannery. Paris: J. Vrin, 1964-1974, vol. X [AT, X].

- Discours de la Méthode. En: DESCARTES, R. Oeuvres complètes. 13 vols. Ed. de Ch. Adams y P. Tannery. Paris: J. Vrin, 19641974, vol. VI [AT,VI].

- Reglas para la dirección del espiritu. Introducción, traducción y notas de J. M. Navarro Cordón. Madrid: Alianza, 1984.

—Discurso del método. Traducción, estudio preliminar y notas de R. Frondizi. Madrid: Alianza, 1980.

Por otro lado tendríamos las fuentes secundarias, es decir, todos los documentos, estudios, libros, artículos, voces de diccionario, artículos en línea, etc., cuya base está en las fuentes primarias, y que hemos consultado y citado en nuestro trabajo. No sirve para nada subdividir este apartado en libros, artículos, o por temas, así que una sola lista que respete el orden alfabético es suficiente. Ofrecemos a continuación algunas normas, basadas en ISO 690 y 690-2, normas que también se aplican a las fuentes primarias. Evidentemente, EndNote o el gestor que hayamos elegido será de gran ayuda en nuestra tarea de elaboración.

10 supra, ap.2. 
No obstante existen algunos detalles que el investigador, el filósofo, debe conocer y modificar en el gestor.

1. La ordenación de las entradas de la Bibliografía sigue unas pautas. Algunas de ellas son las siguientes: a) una entrada con un solo autor se ordena antes que una con más autores participantes; b) las obras de un grupo de autores se ordenan por la fecha de publicación, de más actual a menos actual; c) las diferentes obras de un autor o de un grupo de autores, aparecidas en un mismo año, se ordenan añadiendo a la fecha una letra en cursiva (v.gr.: 2011a, 2011b); d) los documentos que un autor ha publicado como coordinador, director o editor, se ordenan después de aquellos en los que figura como autor, según el orden alfabético de la abreviatura utilizada para designar la función (coord., dir., ed.); e) en el caso de la responsabilidad principal, si se trata de más de dos autores, detrás del primero se pone et al., que significa otros autores; f) si la autoría o responsabilidad principal es editor, director, compilador, coordinador, o editor literario, después del apellido y nombre, añadimos, entre paréntesis, la abreviatura correspondiente al tipo de función que realiza: ed. dir., comp., coord., ed. lit.; g) en el caso de referenciar varios documentos de un mismo autor, reemplazaremos el primer elemento (o zona) de la segunda referencia, y las siguientes, por una raya.

2. Después de la responsabilidad principal (en mayúsculas o versalitas), pondríamos el título (de cursiva) y el subtítulo, si lo tuviera (y empezaría después de dos puntos (:), y cerramos esta zona con un punto (.); aludimos a las responsabilidades secundarias, si las tuviera: prologuistas, traductores, etc., y cerramos con un punto (.); a continuación mencionamos la zona de edición: lugar, dos puntos (:), editorial (sin la mención de editorial), coma (,), y año de edición. Sólo en el caso de que se trate de una edición distinta a la primera se hace mención de ello, abreviándolo (5. a ed.).

3. Después de la responsabilidad principal (mayúsculas o versalitas), el título del artículo de una revista debe quedar de redondo, entre comillas, cerrando esta zona con un punto (.); le sigue el título de la revista en cursiva (no es necesario poner ni in ni en para una revista), cerrando con un punto (.); vienen después el año de aparición, el volumen, el número, y las páginas de comienzo y de final, separando estos elementos con comas (,); las abreviaciones vol., núm. o pp, pueden omitirse, siempre y 
cuando no produzcan confusión; si solo existe el número o el volumen es necesario especificarlo.

4. Para un capítulo o parte de una obra colectiva (o en un diccionario), comenzamos con la responsabilidad principal (mayúsculas o versalitas), y cerrando esta zona con punto (.); le sigue el título del artículo o parte (de redondo y entre comillas), y cerrando con punto (.); le sigue la palabra En y dos puntos (En:), seguido del nombre del editor científico responsable (precedido de ed.) o de la responsabilidad principal (mayúscula o versalitas), cerrando con punto (.) y el título de la obra colectiva (en cursiva), con todos los datos de la zona de edición, sin olvidar finalmente la paginación.

5. Evidentemente, cabe la posibilidad de citar, en la bibliografía de las fuentes secundarias, documentos consultados en internet, si son lo suficientemente serios y fiables, precisando con exactitud no sólo el soporte (entre corchetes [ ]), sino también el URL (Uniform Resource Locator, la dirección internet que comienza por http://) entre antilambdas $(<>)$, y la fecha de la consulta (entre corchetes []).

Para ilustrar todo lo anterior, y siguiendo el Sistema Tradicional, ponemos un ejemplo de asiento bibliográfico de una obra de un autor, de varios autores (con dos opciones), de un capítulo en una obra colectiva, de un capítulo de libro escrito por el mismo autor del libro en cuestión, de dos obras de un mismo autor, y de un artículo de revista (impreso y digital), cuidando al máximo la puntuación entre zonas y elementos, así como la diacrisis tipográfica. No seguimos aquí el orden alfabético.

SIERRA BRAVO, R. Tesis Doctorales y trabajos de Investigación Cientifica. Metodología general de su elaboración y documentación. $5^{\mathrm{a}}$ ed. Madrid: Paraninfo, 1999.

ALVAR EZQUERRA, M.; CASTILLO CARBALLO, M.a A.; GARCÍA PLATERO, J.M.; JIMÉNEZ CUENCA, M.A.; MEDINA GUERRA, A. M. a Manual de redacción y estilo. Madrid: Istmo, 1999.

ALVAR EZQUERRA, M.; et al. Manual de redacción y estilo. Madrid: Istmo, 1999. 
FIGUERAS, C. «La puntuación». En: MONTOLÍO, E. (coord.). Manual práctico de escritura académica. vol. 3. Barcelona: Ariel, 2000, 77-152.

LÓPEZ YEPES, J. «La fase de elección de tema y la titulación del trabajo científico». En: La aventura de la investigación cientifica: guía del investigador y del director de investigación. Madrid: Síntesis, 1996, 82-91.

MARTÍNEZ DE SOUSA, J. Ortografía y ortotipografía del español actual. Gijón (Asturias): Trea, 2004.

- Diccionario de redacción y estilo. $3 .^{\mathrm{a}}$ ed. Madrid: Pirámide, 2003.

MUNOOZ-ALONSO, G. «Identificación de fuentes digitales en la investigación filosófica». Anales del Seminario de Historia de la Filosofía. Madrid: Universidad Complutense, 2008, vol. 25, 171-186.

ESTIVILL, A.; URBANO, C. «Cómo citar recursos electrónicos». [En línea]. Artículo encargado por la Revista Information World en Español. (09-1997. [Barcelona]: Escola Universitària Jordi Rubió i Balaguer de Biblioteconomia i Documentació, 1997. <http://www. ub.edu/biblio/citae-e.htm>. [Consulta: 25 jun. 2012]

Otro de los aspectos sobre el que queremos llamar la atención es el referente a la alfabetización de la responsabilidad principal de los documentos recopilados en la Bibliografía. En principio, el tema de la alfabetización parece no plantear dudas ya que cuando almacenamos bibliografía procedente de bibliotecas o de bases de datos, ya sea manualmente o con ayuda de los gestores bibliográficos, pongamos por caso, con ayuda de EndNote, las fuentes documentales ya están alfabetizadas. No obstante, no hay que confiar absolutamente en las fuentes consultadas ya que los errores de alfabetización son demasiado frecuentes. En una palabra: existen reglas internaciones de alfabetización que no siempre se respetan, lo cual produce una penosa impresión en un trabajo académico; debemos estar alertas al respecto, principalmente cuando se trata de apellidos con conectores o cuando existen varios apellidos.

En la citación a pie de página no tenemos problema, ya que allí no se trata de alfabetizar; sólo colocamos el nombre y el apellido del autor de la fuente (a veces solo el apellido). Pues bien, imaginemos que estamos manejando las siguientes cinco obras: a) un ejemplar de Educación infantil, del pedagogo italiano Severino Fausto de Dominicis (1846-1930); b) la obra La comedia humana, del novelista 
francés Honoré de Balzac (1799-1850); c) la obra El darwinismo, del filósofo alemán Eduard von Hartmann (1842-1906); d) la obra Introducción a la filosofía, del filósofo y psicólogo francés Renée le Senne (1883-1954); y e) el libro coordinado por el catedrático de la Universidad de Oviedo Mario de Miguel Díaz, titulado Metodologías de enseñanza y aprendizaje para el desarrollo de competencias, y que lleva el subtítulo de Orientaciones para el profesorado universitario ante el espacio europeo de educación superior. Pues bien, para su correcta puesta en página, debemos tener conocimiento de algunas normas internacionales, o por lo menos hacer las consultas pertinentes en caso de duda; son numerosos los trabajos e incluso las obras que alfabetizan incorrectamente sus fuentes de información, lo cual da una penosa impresión. Por ejemplo, es preciso saber que en el caso de los italianos los conectores se anteponen, en el caso de los alemanes la partícula von se pospone, y en el caso de los franceses, los artículos se anteponen y las preposiciones se posponen; en español también se posponen las preposiciones. El siguiente cuadro lo ilustra. ${ }^{11}$

BALZAC, Honoré de. La comedia humana. 6 vols. Edición preparada por A. Escarpizo. Barcelona: Lorenzana, 1964-1966.

DE DOMINICIS, Severino Fausto. Educazione infantile: manuale per le mamme e le istitutrici. Milano: Albrighi, Segato. 1900.

HARTMANN, Eduard von. El darwinismo: lo verdadero y lo falso de esta teoría. Traducción por M. Sales Ferré. Madrid: Victoriano Suárez, 1879.

LE SENNE, Renée. Introducción a la fllosofía. Traducción de E. de Amilibia. Buenos Aires: El Ateneo, 1954.

MIGUEL DÍAZ, Mario de. Metodologías de enseñanza y aprendizaje para el desarrollo de competencias: orientaciones para el profesorado universitario ante el espacio europeo de educación superior. Madrid: Alianza, 2006.

\section{Referencias bibliográficas con el Sistema Harvard o APA}

El enunciado de las Referencias bibliográficas (o Bibliografía) en el Sistema Harvard o APA no presenta dificultades. Se trata de anteponer el año de aparición de la publicación correspondiente, colocando ese dato entre paréntesis,

11 cf. Gemma Muñoz-Alonso. Estructura, metodología y escritura del Trabajo de Fin de Máster. 2. ${ }^{\text {a }}$ ed. Madrid: Escolar y Mayo, 2012, 34-39. 
y después de la responsabilidad principal. Es ya habitual utilizar minúsculas, en vez de mayúsculas o versalitas, para el apellido de los autores. No obstante, aquí los ponemos con mayúsculas, en coherencia con el Sistema Tradicional, anteriormente expuesto. Asimismo, el Sistema Harvard, adaptado a la ortografía española, presenta también aquí algunos matices: a) entre un autor y otro se coloca punto y coma; b) si hubiera más de dos autores, se diría et al.; c) después del paréntesis que encierra la fecha se pone punto; d) se utilizan comillas latinas para encerrar un capítulo de una obra, o un artículo de una revista; e) se hace mención de las responsabilidades secundarias; f) se indica el número de edición, a no ser que sea la primera; g) en el caso de un artículo se sigue la secuencia de volumen, número y paginación, pero en el caso de que faltara alguno de esos elementos se indicaría con vol., núm. o pp.; etc. En una palabra: cuantos más datos ofrezcamos al lector, más fácil será recuperar la documentación, y más riguroso será nuestro trabajo. Evidentemente los gestores bibliográficos son una valiosa ayuda pero tenemos que adaptar los parámetros a nuestro campo de estudio y convenciones académicas.

CLANCHY, J.; BALLARD, B. (2000). Como se hace un trabajo académico: guía práctica para estudiantes universitarios. Traducción de A. Garrido y N. Barrantes. 2. ${ }^{a}$ edición aumentada. Zaragoza: Prensas Universitarias de Zaragoza.

FIGUERAS, C.; SANTIAGO, M. (2002). «Planificación». En: MONTOLÍO, E. (coord.). Manual práctico de escritura académica. 3 vols. Barcelona: Ariel, vol. 2, 15-68.

MARTÍNEZ DE SOUSA, J. (2003). Diccionario de redacción y estilo. 3. a ed. Madrid: Pirámide.

MUÑOZ-ALONSO, G. (2008). «Principios teóricos para la evaluación del documento filosófico». Investigación Bibliotecológica. México: UNAM, 22, 45, 41-62.

\section{Referenciación de materiales especiales}

Bajo la denominación de materiales especiales podríamos incluir la citación de material cartográfico, como mapas, planos, atlas, cartas meteorológicas, o fotografías aéreas, pero también fotografías o partituras, o simplemente documentos audiovisuales, y en este último campo tendríamos vídeos, CD-ROMs, DVDs, o programas de radio y televisión. Se trata de materiales cada vez más presentes en 
el terreno de la investigación filosófica, y sobre todo en el campo de la estética. Por esa razón, es menester saber cómo citarlos y referenciarlos.

Existen en la actualidad especialistas y documentos que nos pueden ayudar a la referenciación de estos materiales, como son manuscritos, incunables y libros antiguos, dibujos y grabados, fotografías, microformas, materiales cartográficos, música impresa, grabaciones sonoras, videograbaciones, etc. ${ }^{12}$

En el caso de materiales cartográficos tendríamos los siguientes elementos: a) autoría o nombre de la entidad responsable; b) título (en cursiva); c) designación del tipo de material entre corchetes [ ]; d) otras responsabilidades (opcional); e) escala del documento, proyecciones; f) edición, si no es la primera; g) lugar de publicación, editorial, año de publicación; i) cantidad (del material correspondiente), extensión del documento, medidas, color, etc. (opcional).

Con respecto a una partitura o música impresa (o electrónica) la referenciación tendría los siguientes elementos: a) autoría o nombre de la entidad responsable; b) título; c) designación del tipo de material; d) edición si no es la primera; e) lugar de publicación, editorial y año; f) extensión del documento, medidas, etc.

Los documentos audiovisuales también tienen su formulismo. En este campo entrarían los DVDs, discos compactos, vídeos, CD-ROMs, cintas, cassetes, programas de radio y programas de televisión, etc. En este conjunto hablaríamos de los siguientes elementos: a) autoría o nombre de la entidad responsable, identificando a los principales contribuidores, como el director o el productor, o ambos, pero no los distribuidores de los vídeos o DVDs; b) título; c) designación del tipo de material o soporte; d) edición si no es la primera; e) otras responsabilidades si se considera oportuno; f) lugar de publicación, detallando el país de origen de la película, editorial o nombre del estudio, y año de lanzamiento; g) descripción física, como el tiempo total de duración de la proyección (empleando, por ejemplo 40 minutos o 40:00), la presencia de sonido o ausencia, la velocidad de la proyección, las dimensiones, etc.

A continuación presentamos algunos ejemplos de referenciación de materiales especiales, siguiendo el Sistema Tradicional y el Sistema Harvard o APA. pássim.

12 cf. C. Díez Carrera (coord.). La catalogación de los materiales especiales. España: Trea, 2005, 
Sistema Tradicional:

CHOPIN, Frederic. Nocturnos. [Disco Compacto]. Daniel Barenboim, piano. Auswahl Selection, Deutsche Grammophon Gessellschaft, 2001.70 minutos.

FAURÉ, Gabriel. Impromptu núm. 2, op. 31. [Partitura]. París: Éditions musicales, 1920. 1 partitura en francés y alemán. 5 páginas.

INSTITUTO GEOLÓGICO Y MINERO DE ESPAÑA. Mapa de Candeleda. [Material cartográfico]. Escala 1:50.000. Madrid: Instituto Geológico y Minero, 2000. 1 mapa en 2 hojas. 80x140 cm.

MENÉNDEZ, José María. Sonata en fa mayor para violín. [Música impresa]. Julia Casado, violín. Madrid: Especifica, 2011. 1 partitura. 5 páginas. $22 \mathrm{~cm}$.

RAMIS, Harold (director). Atrapado en el tiempo [DVD]. Reparto: Bill Murray, Andie MacDowell, Chris Elliot, Stephen Tobolowsky, etc.; música: George Fenton. Estados Unidos: Columbia Pictures, 1993. 101 minutos.

UNIVERSIDAD DE OXFORD. Debate Richard Dawkins vs. Arzobispo de Canterbury. Moderado por Sir Anthony Kenny. [Videograbación]. Oxford: Teatro Sheldonian (02-2012). Trad y sub. al español por Fulgencio R2D2. Parte 1/6. <http://www.youtube.com/watch?v=9TP0ErKICzs \& feature $=$ related $>.15: 00$. [Consulta: 16 jul. de 2012].

Sistema Harvard:

CHOPIN, Frederic. (2001). Nocturnos. [Disco Compacto]. Daniel Barenboim, piano. Auswahl Selection, Deutsche Grammophon Gessellschaft. 70 minutos.

FAURÉ, Gabriel. (1920). Impromptu núm. 2, op. 31. [Partitura]. París: Éditions musicales. 1 partitura en francés y alemán. 5 páginas.

INSTITUTO GEOLÓGICO Y MINERO DE ESPAÑA. (2000). Mapa de Candeleda. [Material cartográfico]. Escala 1:50.000. Madrid: Instituto Geológico y Minero. 1 mapa en 2 hojas. $80 \times 140 \mathrm{~cm}$.

MENÉNDEZ, José María. (2011). Sonata en fa mayor para violín. [Música impresa]. Julia Casado, violín. Madrid: Especifica. 1 partitura. 5 páginas. $22 \mathrm{~cm}$. 
RAMIS, Harold (director). (1993). Atrapado en el tiempo [DVD]. Reparto: Bill Murray, Andie MacDowell, Chris Elliot, Stephen Tobolowsky, etc.; música: George Fenton. Estados Unidos: Columbia Pictures. 101 minutos.

UNIVERSIDAD DE OXFORD. (2012). Debate Richard Dawkins vs. Arzobispo de Canterbury. Moderado por Sir Anthony Kenny. [Videograbación]. Oxford: Teatro Sheldonian (02-2012). Trad y sub. al español por Fulgencio R2D2. Parte 1/6. <http://www.youtube.com/watch?v=9TP0 ErKICzs\&feature=related $>$. 15:00. [Consulta: 16 jul. 2012].

\section{Los sistemas de gestión bibliográfica en la gestión filosófica}

En la actualidad, cualquier investigador en filosofía y en ciencias humanas necesita realizar numerosas consultas en bases de datos tanto en línea como en disco compacto pero, una vez realizada la consulta, los registros obtenidos deben ser procesados correctamente para poder obtener de ellos el mayor rendimiento.

Desde hace más de veinte años se ha extendido el uso de softwares que facilitan precisamente la búsqueda, descarga, organización, presentación y personalización de las referencias bibliográficas. Estos programas son de gran ayuda en la actividad académica y científica ya que realizan de forma automática la composición y manejo de listas bibliográficas, así como la elaboración y administración de resúmenes (abstracts) y citas.

Todas estas aplicaciones informáticas ofrecen la posibilidad de capturar registros, formatearlos en el estilo deseado y, posteriormente, transferir esta información a procesadores de texto. Además, estos programas poseen todas las características propias de una base de datos convencional, como por ejemplo: realizar búsquedas por palabras clave, por autor, por título, por materia, etc. Rodríguez Castilla los define del siguiente modo: "Los gestores bibliográficos son aplicaciones informáticas destinadas a manejar bases de datos de referencias bibliográficas obtenidas a partir de distintas fuentes de información: Medline, Mla, EconLit, LISA, catálogos, sitios web u otros, capaces de crear, mantener, organizar y dar forma a dichas referencias según diferentes estilos de citación”. ${ }^{13}$

13 «¿Le resulta difícil hacer la bibliografía? Los gestores de referencias bibliográficas pueden ayudarlo». Acimed, 2009, 19, 2. [En línea]. <http://bvs.sld.cu/revistas/aci/vol19_2_09/aci03209. htm>. [Consulta: 18 jun. 2012]. 
Pues bien, en el mercado existen distintos programas para la gestión bibliográfica y se les conoce, de forma genérica como: Personal Bibliographic Software (PBS), Personal Bibliographic Tools, Personal Research Assistance, Reference Management Software, Bibliographic Management Systems, etc. La mayoría de ellos apareció en la década de los ochenta en Estados Unidos. En el ámbito comercial, los más conocidos son: Procite (o ProCite), EndNote (y EndNote Web), RefWorks, Papers (Apple), Connotea, Citeulike, Zotero, Reference Manager, BixTex, y Biblioscape, entre otros; todos ellos realizan, básicamente, las mismas funciones. Presentamos, a continuación, una panorámica sobre las prestaciones y utilidades de la mayoría de los gestores bibliográficos existentes en la actualidad. En un segundo momento destacaremos las características particulares del gestor más utilizado por los investigadores en filosofía y en ciencias humanas: EndNote (y EndNote Web). No olvidaremos, sin embargo, la ayuda que ofrecen diferentes procesadores de texto a la hora de crear una bibliografía con un estilo determinado o para realizar una referenciación documental a pie de página.

\subsection{Panorámica general: funciones básicas de un gestor bibliográfico}

Antes de decidirse a utilizar uno u otro producto de gestión bibliográfica se deben conocer sus características específicas. Las más importantes a tener en cuenta son 17, que pasamos a enumerar y describir brevemente. No se trata, claro está, de todas las posibilidades que ofrecen estos productos, pero sí de las más relevantes. ${ }^{14}$

1. Posibilidades de acceso y compatibilidad: si está disponible desde el interior del campus universitario, si el centro académico proporciona copias con licencia individuales o para grupos de trabajo, si es descargable mediante la web, si se requiere descargar o actualizar algún software, o bien si tiene un precio razonable. Por ejemplo, Connotea, Citeulike, o Zotero son gestores gratuitos. ProCite, EndNote, Reference Manager, etc. son programas que puede comprar el usuario. No obstante, la mayoría de los centros de investigación y universidades permiten al investigador utilizarlos o bien le proporcionan licencias a través de los servicios informáticos. Refworks, por su parte, es una aplicación web que

${ }^{14}$ cf. Sonia Muñoz-Alonso. Sistemas de gestión bibliográfica: ProCite. Madrid: Fragua, 2004, pp. 9-11. 
no requiere descargar ni actualizar ningún software, y se puede acceder a una cuenta personal desde cualquier ordenador conectado a la red.

2. Otro aspecto es el referente a las guías de uso y ayuda: si existen manuales acerca de su uso, documentos que expliquen con claridad su potencialidad, o la existencia de una ayuda guiada (Guided Tour) para aprender a usar el programa. La calidad del manual del usuario es importante, y debe ser simple y legible. Asimismo, hay que tener en cuenta la disponibilidad de una herramienta de ayuda sensible al contexto.

3. El número de bases de datos que puede gestionar y el número máximo de caracteres por campo y por registro varía de un gestor a otro, y puede ser interesante tenerlo en cuenta.

4. La posibilidad de crear o modificar plantillas predefinidas para la entrada de datos permite a muchos investigadores personalizar las bibliografías o bibliotecas en función de la especialidad. Es importante que sean flexibles para añadir o quitar nuevos campos.

5. En la mayor parte de los gestores la inserción de datos puede ser manual o por captura de registros de otras bases de datos, tanto en línea como en disco compacto.

6. La variedad de filtros de importación y la posibilidad de ser diseñados o modificados por el propio usuario, son aspectos a tener en cuenta ya que, a veces, no es suficiente con los filtros predefinidos en el programa.

7. Las últimas versiones de los gestores bibliográficos presentan la capacidad de incluir distintos tipos de registros, y de tamańo variado, en una misma base de datos: libros, artículos de revistas, ponencias a congresos, páginas web, blogs, fotografías, imágenes, panfletos, bases de datos, catálogos, etc.

8. La capacidad para ordenar y agrupar los registros de nuestra base de datos supone una gran ventaja para el investigador tanto a corto como a largo plazo. 
9. Todos los programas permiten recuperar la información a través de distintos campos, tanto predefinidos como definidos por el usuario. Para hacer más efectiva la búsqueda, pueden emplearse operadores booleanos.

10. Los gestores permiten la visualización, impresión y exportación de registros. Tanto el formato de visualización como el de impresión deben ser modificables y ofrecer diversas posibilidades de presentación (como en un procesador de texto).

11. No todos los programas son cómodos para el usuario. Hay que tener en cuenta, pues, no sólo el uso intuitivo del programa, sino también la existencia de una interface visual consistente y amigable.

12. La compatibilidad con procesadores de texto para recuperar citas y listas de referencias es un factor a tener en cuenta. En efecto, la mayoría de los gestores permiten organizar las fuentes de información consultadas e interactuar con procesadores de texto, como Word y Open Office Writter, y así se puede generar de forma automática la cita o la bibliografía en el cuerpo del documento.

13. La posibilidad de exportación de la base de datos creada por el usuario a otros paquetes informáticos puede realizarse en la mayoría de los gestores.

14. Hay que prestar atención a la versión del gestor ya que debe ser compatible con el sistema operativo del ordenador del usuario; por ejemplo existen gestores incompatibles o creando dificultades con las nuevas versiones de Windows.

15. La posibilidad de originar listas de referencias (o bibliografía) a partir de bases de datos personales, es algo imprescindible desde el punto de vista académico y además, poderlas adecuar a los diferentes estilos de citación que utilizan las revistas o bien los diversos campos científicos. Los gestores de referencias bibliográficas permiten crear bibliografías o introducir listas de referencias dentro de un manuscrito de forma automática. Ahora bien, la cantidad de estilos de citación incorporados varían desde los más comunes, como el estilo Vancouver, Harvard, MLA, Turabian o Chicago, hasta programas que incluyen más de cien estilos clasificados según la revista que lo recomienda, lo cual es fundamental en determinados 
campos. Con las referencias en nuestro poder podemos generar listas en el estilo de citación que hemos seleccionado, listas que luego pueden ser enviadas a la impresora, a pantalla o a un archivo de texto en formato ascii o de los procesadores de texto más comunes.

16. También hay que tener en cuenta la compatibilidad entre los distintos gestores bibliográficos utilizados ya que puede ser interesante, en ocasiones, poder incorporar registros elaborados con un gestor distinto al habitual. En este sentido, ProCite, Reference Manager y Endnote, aunque son programas diferentes, son compatibles entre sí, en tanto en cuanto permiten importar bibliografías de un programa al otro.

17. Otro aspecto importante es la personalización a la hora de tratar y manejar los duplicados de registros durante el procesamiento de la información.

Con respecto al Copyright, existe un vacío legal sobre el número de registros que un usuario puede capturar. Sin embargo, el hecho de que existan plantillas predefinidas para cada casa distribuidora (SilverPlatter, Dialog, ISI, etc.) permite suponer que éstas están de acuerdo en la legalidad de la transmisión de su información.

Para ver una comparación detallada entre diversos sistemas de gestión bibliográfica, se pueden consultar numerosos documentos. Destacamos los siguientes, si bien el lector puede consultar otros documentos que presentamos en la bibliografía final del artículo:

- Gestores de referencias bibliográficas: Grandes aliados. [En línea]. (03-122007). <http://www.absysnet.com/tema/tema66.html>. [Consulta: 25 jun. 2012].

- Maggie Shapland. Evaluation of Reference Management Software on NT (comparing Papyrus with ProCite, Reference Manager, Endnote, Citation, GetARef, Biblioscape, Library Master, Bibliographica, Scribe, Refs). [En línea]. (1999). <http://www.cse.bris.ac.uk/ ccmjs/rmeval99.htm>. [Consulta: 18 jun. 2012].

- Biblio Tech. Review. Information Technology for Libraries. Personal Bibliographic Managers. [En línea]. <http://www.biblio-tech.com/html/pbms. html>. [Consulta: 18 jun. 2012]. Peter Evans presenta aquí un estudio 
titulado «Review of 3 major Personal Bibliographic Management tools» llegando a la conclusión de que el mejor gestor es ProCite y Reference Manager (4 puntos), frente a EndNote (3 puntos).

- Además, en la página web de la empresa Sistemas Documentales (<http://www.sisdoc.es $>$ ) se puede conseguir demostraciones gratuitas por un mes (shareware) de algunos de estos programas, así como tutoriales de EndNote, EndNote Web, y Reference Manager. $<$ http://www.sisdoc.es/producto.php?id=48>. [Consulta: 25 jul. 2012].

\subsection{EndNote y EndNote Web: una nueva manera de investigar}

El gestor EndNote (y EndNote Web) se ha convertido en el producto estrella de los últimos años. En líneas generales puede afirmarse que este programa cumple con los 17 requisitos que hemos señalado anteriormente.

Destacamos, a continuación, las principales ventajas de EndNote en sus dos modalidades:

- Aunque no es gratuito la mayoría de las universidades españolas y centros de documentación permiten su uso o bien conceden licencias a los investigadores.

- Compatible con otros gestores bibliográficos, como ProCite o Reference Manager.

- Bastante intuitivo en sus últimas versiones. Actualmente contamos con la versión mejorada de X6.

- Existencia de tutoriales esclarecedores para conocer los entresijos del programa. En YouTube se encuentran tutoriales subtitulados de gran calidad.

- Trabaja con Windows y Mac OS X

- Consigue localizar artículos pdf completos de manera automática, e incorporar esos documentos en la biblioteca creada por el usuario. 
- Interactúa con procesadores de texto de forma ágil y fácil, tanto con el Word como con el OpenOffice Writter, generando de manera automática la cita a pie de página (o al final del trabajo) o bien la bibliografía en el cuerpo del documento que se está elaborando.

- Permite escoger entre más de tres mil estilos de citación, dependiendo de la materia o de las instrucciones de revistas académicas y científicas.

- Ofrece la posibilidad de comprimir la biblioteca y crear un archivo adjunto para enviarlo por correo electrónico.

- Posibilita crear los llamados Smart groups, donde se pueden organizar las referencias en subconjuntos sobre la base de ciertos criterios propios. Este aspecto es muy interesante para grupos de investigación ya que dos o más personas pueden intercambiar documentación e incorporarla a un proyecto aunque utilicen procesadores de texto distintos.

- El usuario puede trabajar con todas las prestaciones de esta herramienta desde su casa o desde cualquier lugar, siempre y cuando tenga acceso a la red.

En resumen, por su facilidad de uso y por su versatilidad se ha convertido en el gestor más utilizado para búsquedas y organización de referencias, archivos pdf e imágenes y para crear bibliografías.

\section{Otros recursos o productos interesantes}

- Word tanto para Mac como para Windows. El procesador de textos Word de Microsoft Office integra, desde su versión 2007, un gestor bibliográfico, localizable en el menú Referencias, que puede resultar útil también para determinados usuarios. No obstante, da prioridad a dos estilos: APA y MLA, en sus versiones anglosajonas.

- Latex (o LaTeX). Es un procesador de texto, de gran potencialidad en el manejo de fórmulas matemáticas, cuadros y tablas. Además de sus capacidades gráficas para representar ecuaciones, fórmulas complicadas, notación científica e incluso musical, permite estructurar con facilidad el documento (capítulos, secciones, notas, bibliografía, índices analíticos, 
etc.), lo cual supone una gran comodidad y lo hace especialmente útil para artículos académicos, tesis doctorales y libros técnicos. La calidad tipográfica de los documentos realizados con este procesador de textos es comparable a la de una editorial científica de primera línea. LaTeX es software libre bajo licencia LPPL. ${ }^{15}$

\section{Conclusión}

A lo largo del artículo hemos podido vislumbrar algunos de los aspectos que hay que tener en cuenta a la hora de realizar un trabajo académico en el campo de la filosofía que sea riguroso, preciso y fiel a las fuentes de información utilizadas para su elaboración. Cualquier trabajo que acometamos, sea cual sea su nivel de profundidad, necesita unos rasgos formales sin los cuales ni el autor ni el lector entenderían el mensaje. Tales rasgos van desde una correcta puesta en página, con unos párrafos bien definidos visual y significativamente, unos acertados marcadores textuales que guíen la lectura y sirvan para afianzar los argumentos, y, por supuesto, un aparato crítico jugoso que demuestre nuestra habilidad en la citación de fuentes, en el análisis de los textos, y en el gusto intelectual para la elección de los mismos. Los gestores bibliográficos son herramientas básicas para que el proceso de investigación sea una tarea enriquecedora y científica ya que el reconocimiento de los materiales que cimentan y contribuyen a la realización del trabajo académico es requisito indispensable desde el punto de vista ético y legal. Ahora bien, en muchas ocasiones el investigador puede y debe personalizar el estilo elegido, siendo los más comunes el Tradicional o MLA, y el APA o Harvard, susceptibles de ligeros cambios ortotipográficos que enriquecerán el trabajo académico. Por supuesto, las revistas científicas tienen su particular manera de citar y referenciar. La ventaja de los gestores radica en que recogen centenares de normas de esas revistas científicas, de las más prestigiosas, lo cual facilita la tarea bibliográfica; en tales casos la personalización no tiene sentido ya que el estilo viene impuesto por la revista, la editorial o la institución correspondiente. Por supuesto, una vez elegido un estilo todas las citas y referencias del trabajo en cuestión deben seguir ese estilo y, en consecuencia, guardar uniformidad en la presentación.

15 cf. <http://www.fceia.unr.edu.ar/lcc/cdrom/Instalaciones/LaTex/latex.htm>. [Consulta: 18 jun. 2012]. 


\section{Bibliografía}

American Psychological Association. APA. Electronic reference formats recommended by the American Psychological Association. [En línea]. <http://www.apastyle.org/elecref.html>. [Consulta: 5 jul. 2012].

Caron, Rosaire. "Comment citer un document électronique?». En: Université Laval. Bibliothèque. Bibliothèque de l'Université Laval. [En línea]. <http://www.bibl.ulaval.ca/doelec/citedoce.html>. [Consulta: 6 jul. 2012].

Dewey, R. A. APA Style Resources. [En línea]. <http://www.psychwww.com/resource/apacrib.htm>. [Consulta: 8 jul. 2012].

Díez Carrera, C. (coord.). La catalogación de los materiales especiales. España: Trea, 2005.

Estivill, A.; Urbano, C. «Cómo citar recursos electrónicos» [en línea]. Artículo encargado por la Revista Information World en Español. (09-1997). [Barcelona]: Escola Universitària Jordi Rubió i Balaguer de Biblioteconomia i Documentació, 1997. <http://www.ub.edu/biblio/citae-e.htm>, [Consulta: 16 jul. 2012].

Gibaldi, J. MLA Handbook for Writers of Research Papers. 7th edition. New York: Modern Language Association of America, 2009.

Gingras, F.-P. Comment citer des sources sur Internet dans un travail scientifique.[En línea]. (21-03-2005). <aix1.uottawa.ca/-fgingras/metho/citation.html>. [Consulta: 10 jul. 2012].

Grafton, A. Los orígenes trágicos de la erudición. México [Etc.]: FCE, 1998.

Harnack, A.; Kleppinger, E. Beyond the MLA Handbook: Documenting electronic sources on the Internet. Eastern Kentucky University, Richmond, KY, [En línea].(1006-1996). <http://english.ttu.edu/kairos/1.2/inbox/mla_archive.html>. [Consulta: 5 jul. 2012].

Ifla/Iflanet. Style Guides and Resources. [En línea]. (25-10-2005). <http://www.ifla. org/I/training/citation/citing.htm>. [Consulta: 9 jul. 2012].

ISO 690:2010. Information and documentation. Guidelines for bibliographic references and citations to information resources. [En línea].

<http://www.iso.org/iso/catalogue_detail.htm?csnumber=43320>. [Consulta: 12 jul. 2012].

Lamarca Lapuente, M. Jesús. Hipertexto: El nuevo concepto de documento en la cultura de la imagen.

[En línea]. (1997). <<http://www.hipertexto.info/documentos/modelo_citas.htm>. [Consulta: 3 jul. 2012].

Land, T. Web Extension to American Psychological Association Style (WEAPAS). Proposed standard for referencing online documents in scientific publications. [En línea]. (1510-1998). <http://www.beadsland.com/weapas/ >. [Consulta: 5 jul. 2012]. 
Martínez de Sousa, J. Manual de estilo de la lengua española. Gijón (Asturias): Trea, 2000.

Merlo Vega, J.A. «Estilos de citas y referencias de documentos electrónicos». Artículos. [En línea]. Salamanca: Facultad de traducción y documentación. Universidad de Salamanca (22-02-2001). <http://exlibris.usal.es/merlo/escritos/citas.htm>. [Consulta: 18 jul. 2012].

Modern Language Association. MLA style. [En línea]. <http://www.mla.org/>. [Consulta: 10 jul. 2012].

Muñoz-Alonso, Gemma. Estructura, metodología y escritura del Trabajo de Fin de Más-

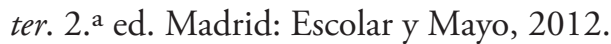

Muñoz-Alonso López, Sonia. Sistemas de gestión bibliográfica: ProCite. Madrid: Fragua, 2004.

Rodríguez Castilla, L. "¿Le resulta difícil hacer la bibliografía? Los gestores de referencias bibliográficas pueden ayudarlo». Acimed, 2009, 19, 2. [En línea]. <http://bvs.sld. cu/revistas/aci/vol19_2_09/aci03209.htm>. [Consulta: 1 jun. 2012].

Salgado García, E. Guía para elaborar citas y referencias en formato APA. [En línea. Documento en pdf]. Costa Rica: Universidad Latinoamericana de Ciencia y Tecnología. (Enero 2012). <http:// www.ulacit.ac.cr/.../...>. [Consulta: 10 jul. 2012]

Universidad De Alcalá De Henares. Biblioteca. BUAH. Estilos de citas. [En línea]. <http://www.uah.es/biblioteca/ayuda_formacion/estilos_citas.html>. [Consulta: 2 jul. 2012].

Universidad Carlos III de Madrid. Biblioteca. Cómo citar bibliografía: una guía de la Biblioteca de la Universidad de Carlos III de Madrid para estudiantes ante su Trabajo de Fin de Grado. [En línea y en pdf]. http://www.uc3m.es/portal/page/portal/ biblioteca/aprende_usar/como_citar_bibliografia>. [Consulta: 12 jul. 2012]

Universidad de La Laguna. Biblioteca. Cómo citar. [En línea]. (03-07-2012). <http:// www.ull.es/view/institucional/bbtk/Como_citar_1/es>. [Consulta: 5 jul. 2012].

University of Alberta Libraries. Citation style guides for Internet and electronic sources. [En línea]. (04-07-2012).

<http://www.library.ualberta.ca/guides/citation/index.cfm >. [Consulta: 1 jul. 2012].

Recibido: 13/10/2011

Aceptado: 28/07/2012 